\title{
Parametric Modelling of Steel Connectors in a Glulam Based Post and Beam Building System - Towards a Flexible Product Platform Approach
}

\author{
Shamnath THAJUDEEN ${ }^{\mathrm{a}, 1}$, Martin LENNARTSSON ${ }^{\mathrm{b}}$, Fredrik ELGH ${ }^{\mathrm{a}}$ and \\ Per Johan PERSSON ${ }^{\mathrm{c}}$ \\ ${ }^{a}$ Department of Industrial Product Development, Production and Design, School of \\ Engineering, Jönköping University, Gjuterigatan 5, 55318 Jönköping, Sweden \\ ${ }^{\mathrm{b}}$ Department of Building Engineering and Lighting Science, School of Engineering, \\ Jönköping, University, Gjuterigatan 5, 55318 Jönköping, Sweden \\ c Moelven Töreboda, Sweden
}

\begin{abstract}
House building projects are distinctive, and the degree of customisation creates bottlenecks in the design process and challenges for production, which results in longer lead time and higher costs. Aligned with a product platform approach, previous studies have introduced cost-effective approaches such as standardisation, modularization, configurators, etc. Still, components that cannot be completely modularized and configured due to high complexity level, may require a lot of engineering efforts during development. A platform approach that can be used to support engineer-to-order products that change over time still needs to be explored. The application of parametric modelling to automate the design process in the construction industry has the potential to further increase both the design and production efficiency. Thus, the objective of this research is to apply parametric modelling in the design of steel connectors used in a glulam based post and beam building system as part of a flexible product platform for increased design and production efficiency. A single case study has been carried out with a Swedish multi-storey house building company. Empirical data were gathered from a workshop with the design team followed by interviews, and document analysis. A computer-supported method for the steel bracket connectors has been developed, that connects post and beam components with pre-defined rules and constraints as part of the platform development. The result contributes to expanding knowledge about the development of a flexible product platform for improved design process and downstream production of customised components with parametric modelling support in the industrial post and beam buildng system.
\end{abstract}

Keywords. Industrialised house building, Product platform, Parametric modelling Engineer-to-order, Building Information Modelling, Glulam, Post and beam.

\section{Introduction}

The housing market in Sweden has been undergoing a substantial price increase. The general price level in Sweden is relatively high compared to many other European

${ }^{1}$ Corresponding Author, Mail: shamnath.thajudeen@ju.se. 
countries [1]. The growing production costs of house building have been highlighted as a major barrier for the housing market [2]. In fact, companies are constantly looking for approaches to increase productivity and manage the frequently increasing cost [3]. Several initiatives have been performed to increase the efficiency of production and to solve on-site issues as part of continuous improvement. However, the design phase of industrialised house building (IHB) is generally perceived as being inefficient and timeconsuming [4] and found as the bottleneck of productivity in building construction [3, 5]. The role of product descriptions have changed over time and more and more tailormade products lead to generate concepts such as engineer-to-order (ETO), modify-toorder (MTO), configure-to-order (CTO) and select variant [6, 7]. Customization or unique needs from the customer has been identified as a common challenge facing by the IHB industry [8], where projects differ with unique requirements over time. Product platform strategies and standardisation efforts have had a significant impact on the development time and cost reduction $[9,10]$. Together with a product platform approach, many previous studies have introduced approaches such as modularization, configurators, etc. that supported to a great extent to become cost-effective. However, some components that cannot be completely modularised and configured due to its high level of complexities required a lot of engineering activities during its development. Transdisciplinary engineering can be supported by a disciplinary ability to respond to different stakeholder's needs and demands. Engineering methods for improved ability to design and manufacture customized solutions could potentially support engineers and construction companies to contribute in transdisciplinary development projects. Platform approach for the component-based product where reusing of design assets has already been a research topic and this is more accountable for the standard products. In other words, a platform strategy that can be used to support the customised product that changes over time still needs to be explored [11,12]. Thus, there should be some dedicated support that could be used to deal with products having ETO nature and to design it more efficiently and ensure producibility.

Companies start to see the benefits of digitalization in construction design and today's CAD systems can be applied for much more than $3 \mathrm{D}$ modelling and the generation of drawings [13]. It is possible to automate the design process if the construct of any complex artefact is suitably restricted by adhering to a library of predefined components and assembly details [14]. In the building industry, the implementation of design automation has increased productivity [15] by using parametric modelling to automate Building Information Modelling (BIM) [16]. Thus, the objective of this research is to apply parametric modelling in the design of steel connectors used in a glulam based post and beam building system as part of a flexible product platform for increased design and production efficiency.

\section{Theoretical background}

A product platform is a collection of assets, which are shared by a set of products sorted into components, processes, knowledge and relationships $[9,10]$. They pointed out the benefit of the platform that, "by sharing components and production processes across a platform of products, companies can develop differentiated products efficiently, increase the flexibility and responsiveness of their manufacturing processes, and competitive in the market with competitors that develop only one product at a time." The concept of design assets offers a new way for efficient customisation, reuse and standardisation by 
introducing and structuring platform elements that are traditionally not used in a platform setting [12]. The concept of flexible product platform is first proposed by Suh, De Weck [17]. Flexibility is defined as "the property of a system that is capable of undergoing specified classes of changes with relative ease" (ibid). The flexibility of a product platform is its capability achieved by modifying parameters of flexible elements [18].

BIM is not only a computer application supporting the $3 \mathrm{D}$ object modelling of buildings, but also allows both automatic parametric generation of designs that respond to various criteria and the prospect of computer-interpretable models and automated checking of designs after they are generated [19]. The knowledge representation during the design phase is certainly becoming an important issue in the area of design automation [14]. Eastman, Lee [20] emphasises that the rule-based systems apply rules, constraints or conditions to a proposed design. Parametric Design is "the process based on algorithmic thinking that enables the expression of parameters and rules that, together, define, encode and clarify the relationship between design intent and design response" [21]. Parametric modelling feature permits regeneration of geometry based on geometrical constraints [22] and allows to integrate domain-specific knowledge using explicit mathematical expressions [16]. According to Singh, Gu [23] the modelling and technical flaws can be reduced as the set of rules for building modelling are predefined using parameters in BIM. Implementing Parametric and Generative Design techniques in Glued laminated timber (GLT) could improve the overall efficiency and can be considered an effective tool for improving the capabilities of design and manufacturing processes in the building industry [24]. Parametric constraint-based design within BIM platforms offers an automatic design validation, where the model is automatically updated to adapt changes [25].

\section{Research Methodology}

The research framework used for this study was Design Research Methodology (DRM), proposed by Blessing and Chakrabarti [26]. This DRM framework comprises four iterative stages used for conducting research in the engineering design field. DRM is used as a framework for the entire research project and this article presents the outcome of the two final stages of DRM with an emphasis on the Prescriptive stage. The support was proposed to improve the current state of the design process in the case company in the prescriptive study stage and an initial evaluation was done with the designers as part of the descriptive study II phase.

The study was qualitative in nature with a combination of a literature survey and a single case study by linking a Swedish multi-storey house building company. Empirical data was collected from a workshop, semi-structured \& unstructured interviews and document analysis. A workshop session was conducted by including both design engineers and the management team. This section initially helps to brainstorm the needs, current challenges facing and to understand the vision to achieve from the company point of view. A project team has been formed as an outcome from the workshop with the aim of different development and improvement activities where the case of steel connectors was in the priority list. The team includes a CAD programmer, two structural engineers and the researcher. In addition, four semi-structured interviews were conducted with key persons who have extensive experience from the design department. The respondents were: the design manager, senior structural engineer, CAD programmer, and structural engineer. Additionally, unstructured interviews were conducted with the key designer 
on a frequent basis in order to understand the current knowledge, challenges and opportunities during the design of connectors. The interviews were audio-recorded and transcribed before the materials were analysed. Document analysis was initiated parallel with the interviews to get in-depth knowledge about the previous projects. Documents related to the design of the connectors from previously finished projects were reviewed. The reviewed documents include building models, part drawings, design templates, bill of materials, component library etc. The bracket connection was chosen as the experimental object where the parametric modelling was applied. At first, the standard parameters and dimension for the bracket connection were formulated from the weekly meeting with the project team. The algorithm was developed as a Plug-in application connected to the BIM tool (Tekla Structures) using Visual Basic (C\#) and the open API in Tekla Structures with the support of CAD Engineer. The input parameters for the connection are defined with user interface (UI) support of Plug-in used in Tekla. Finally, an initial evaluation was carried out with the designers to verify the results generated.

\section{Case company description}

The case company is one of the leading manufacturers of glued wood in Europe. They developed a unique building system on the multi-stored house building market and launched it in 2007. The system was developed based on the prefabrication technique and named as Trä 8 building system and can be used for up to 8 -meter span. This building system can be categorized in the timber based post and beam type of industrial building. The fundamental part of the system is the idea of "Big Size Pre-Cut", where a high level of prefabrication of large building elements and sets of material is developed through efficient production. The main components of the building system include of post, beams, trusses for stabilization which is made of glued wood, floor elements and roof elements made of Kerto material and glulam, and steel connectors. GLT is a widely used structural engineered building material composed by at least two parallel laminations of wood which may include one or two boards next to each other (BS EN 14080:2013).

\section{Case findings - Design of steel connectors used in the buiding system}

Steel connectors are precisely engineered components used to transfer loads from one component to another component. They are used, for instance, to transfer loads from different floors to the foundation through the vertical columns. Each connector is designed to function in different ways and to transfer different magnitude of loads from the building to the foundation. There are four main types of connectors commonly utilized in the building system by the case company as shown in Figure 1.

(1) Column footing: This is the most common type of column footing connection for the building system. On top of a cast-in reinforced steel plate, a second plate with 4 threaded rods are welded on site. The column is delivered with a third plate mounted in the factory using glued-in threaded rods. The third plate uses nuts and washers and the lower washer could be levelled using a plane laser before erecting the column.

(2) Column footing with trusses: When trusses are used in the building, this type of connection is ideal for footing. Trusses are connected to the column footing with the use of dowels. First, the welded plate is mounted with the column in the factory and then, the whole assembly is connected to the reinforced concrete with foundation bolts at site. 
(3) Bracket: This type is used to connect the column with the beam in the building system. The main purpose of these connectors is to transfer the loads from the floors to the vertical columns. Additionally, they function in transferring the horizontal and vertical loads to the wooden trusses.

(4) Truss connection: To stabilize the building structure from the horizontal loads, wooden trusses are used. The element consists of two columns with beams and diagonals connected with slotted in steel plates fastened with dowels.

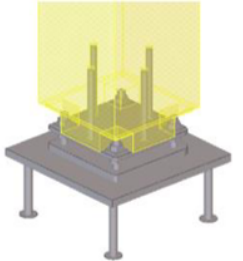

1. Column footing 2. Column footing with truss

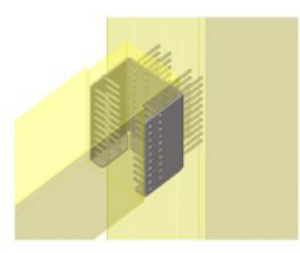

3. Bracket

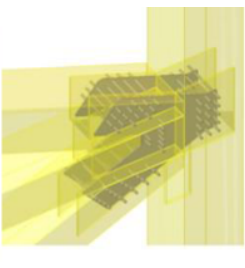

4. Truss

Figure 1. Different types of steel connectors used in the building system.

The connector design process generally involves structural design and modelling of connectors as shown in Figure 2. The structural design normally begins by understanding the scope of the project and the different requirements of the customer, i.e., type of building, number and height of floors, apartment details etc. Identifying the different loads acting in the building is the first step of the structural design. This includes ordinary forces from all loads such as dynamic loads, static loads and special loads. Loads imposed on the building should be transferred to the foundation to keep the building stable. Therefore, connectors can be considered as the most critical component of the building system, to transfer both vertical and horizontal forces.

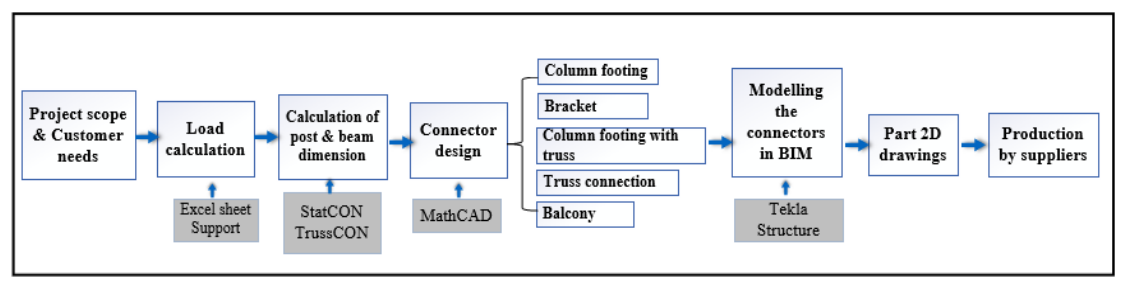

Figure 2. Design process of the steel connector.

The subsequent step is to find out the dimension of glulam post and beam where STATCON or TRUSSCON is used as the tool for performing it. The calculation starts with the beam as the dimension of the beam is necessary to calculate the dimension of the post. The design of connectors can be made when the required loads and dimension of members are calculated. Math CAD is used to design different types of connectors. For example, the vertical load, horizontal load, the dimension of beam and size of screws that goes into the post are the main input data for calculating the brackets. The bracket design is governed by the load calculation. First, the dimension of beams is calculated for the entire structure. For simplicity, the value of different dimensions is kept as low as possible. Once the dimensions of beams are decided, the structural engineer can determine the amount and length of screws needed for each beam cross-section. The modelling of brackets is initiated when the modelling of beam and column members has been completed. This is because the information about the number of screws can only determine from the beam profile. The longest beam with a higher force is often used as a reference for all other beams with a similar height to avoid the calculation of individual 
beam separately. Likewise, different variants of brackets can be reused in different parts of the building. Connectors for balcony is not included in the building system as it differs depending on the customer requirements. The next step is the modelling phase and all these values are forwarded to CAD designer as AutoCAD drawings, who take care of the modelling of building and detailing of different components. Tekla Structures is used as a tool for modelling the whole building and creating a fully detailed production model of the building components. The program generates $2 \mathrm{D}$ drawings and machine files using the information in the building model. Finally, all the drawings and values in digital format are forwarded to the suppliers who produce the connectors. For some connectors, pre-assembly is required before the final assembly on site. The collision between different elements in the connector has been recognized as the major challenge in the design. So adequate control is required while defining different parameters and its dimensions. Moreover, any change in the size of members or the height of the floor would generate a new variant of bracket which is the main challenge for designers.

\section{Application of parametric modelling in the bracket connection}

The prescriptive research activity has been conducted through two main stages: coding the method and testing the algorithm for modelling. The bracket connection was selected as the modelling object as this is one of the commonly used and challenging components of the existing platform and manual modelling is time-consuming and prone to errors. The first phase refers to programming the parametric algorithm for brackets in a Visual studio, where the parameters were defined with rules, constraints, dependencies and boundary conditions. To perform its calculations, the algorithm requires specific inputs that must be manually created. For designing the brackets, the most significant inputs are the value of the horizontal and vertical load, the dimension of primary (post/column) and secondary members (beam) and number of screws on the members. A logic has been followed while programming to create the rules for the parametric features of the brackets. In this stage, all the standard parameters and their respective dimensions of the bracket connections have been defined. The rules and constraints that govern the different design have been set with many alternative conditions. Coding begins with defining the values as in the table shown in Figure 3.
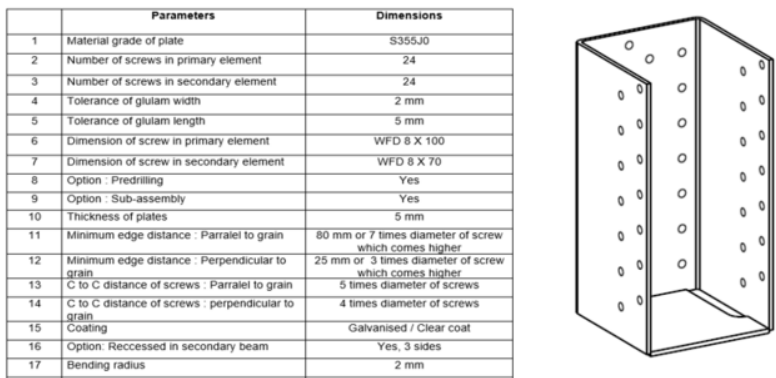

Figure 3. Standard parameters and dimensions for bracket connection.

The next step was to specify different coordinates of brackets. Then, add plates to different coordinates in order to merge with the plates. The thickness of the steel plates is always $5 \mathrm{~mm}$ and it never changes. Subsequently, postion of different holes and details of screws that should be generated in the plate are specified. Finally, the cutting of the beam is also defined to ensure that the beam is properly seated in the bracket. 
The second stage was the testing phase and the use of the algorithm in the BIM environment (Tekla structures). Here, the algorithm performs a geometry analysis to identify the key inputs for further process. The bracket is then inserted to the BIM-model using the Plug-In application where the CAD-engineer can specify the information about the needed screws in the UI of the Plug-In. The size of the beam and column is fetched into the Plug-in from the model. Using this approach, the connection is geometrically dependent and placing of the beam and column and will adapt to any changes of location or dimension. When using parametric modelling in BIM, there are four steps to follow, 1. Select the primary member, 2 . Select the secondary member, 3. Add the number of screws in the primary and secondary members, 4. Select the type of screws. These parameters are the input values provided in a dialogue box, as shown in Figure 4.

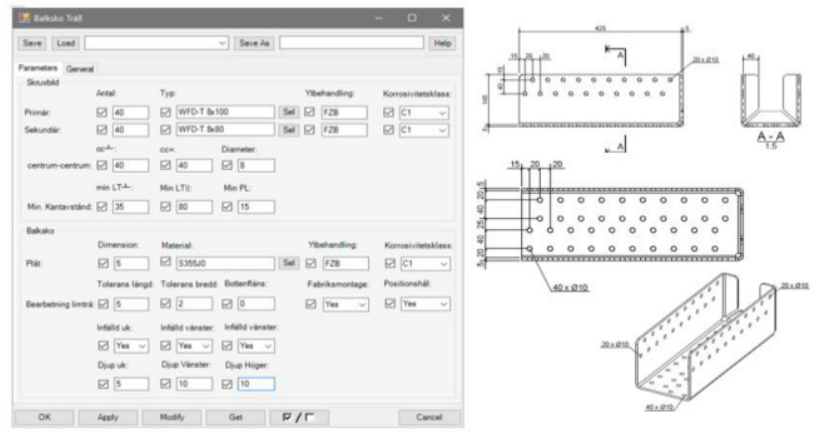

Figure 4. Parametric representation of bracket connection.

The procedure for generating other types of brackets is generic, and the variants would depend on the beam size used in different parts of the building structure. When designing the brackets, the algorithm automatically checks the rules that are based on the configuration of the objects, their relations or attributes. Here the width of the beam basically decides the number of screws that should generate in the bracket, which in turn governs the height of the bracket. How many screws that can fit in one row would decide the height of the bracket. The algorithm will detect the number of screws and adjust the real height to avoid the collision. It is important that the height of the bracket should be less than the height of the beams. The distance to the first row of the screw is specified from this top of the beam. The primary screws from both sides should be short enough to avoid the collision. Therefore, it is important to define the code with a correct offset in order to avoid the collision. However, designers run a verification check to confirm any collision between screws. The same variant of the connector can be generated in different parts of the building if the beam size is identical. The rules are defined for adapting by itself. Thus, the designer can save time and effort by avoiding the repetaed design of the same connectors. If the size of the beam is different, the parameters should change, and the bracket will follow the predefined set of beam sizes and generate a new solution. Thus, there should be different codes for different types of connections.

\section{Discussion}

The analysis of building components shows that the modelling and detailing of steel connectors accounts most of the design time, which was acknowledged by the respondents. The case company produces glulam components and all associated designs 
are relatively standard. However, steel connectors were identified as the most challenging part of the building system. About $20-30 \%$ of the time would be sufficient to design all other components of the building system such as glulam post, beam and, floor elements and remaining is dedicated for the connectors. CAD engineer states that "the technical detailing of connectors remains as a challenge as new connectors have been designed in every project". Currently, limited support is available to streamline the design process and challenging to reuse variants within and across projects. The main reason is changing requirement of the building structure over time and the connectors projects an engineer-to-order characteristics [7]. Therefore, the company was in need of a distinct strategy to improve productivity in the design process. One type of code has been created for the bracket connection, from which several variants of connectors can be generated. So, this can be considered as a design asset in a platform for the bracket connection from which different sets of solutions can be derived [12].

The main objective of this study was to improve the current way of connector design and increase the ability to respond more quickly to customer-specific requirements to enhance producibility. An initiative was taken by the project improvement team by applying the parametric modelling approach in bracket design. The analysis reveals that this modelling approach can be related to a product platform explained by Meyer [9], from which a stream of different variants of connectors can be efficiently developed and produced with an emphasis on the knowledge assets defined by Robertson and Ulrich [10]. In other words, different bracket variants can be derived from the same platform, by predefining the knowledge assets [14] and specify the standard process to execute it. Here, reuse is achieved not by sharing the components rather by sharing the knowledge asset [12] which is pre-defined by various set of rules and constraints using the algorithm $[16,22]$. The flexibility of the proposed product platform is the ability to rapidly generate a design solution to accommodate both predicted and unforeseen changes through the reuse of design knowledge and computational methods [18]. On this developed platform, knowledge assets are predefined in such a way that the connector can be created that can adapt to dynamic customer requirements by adjusting its structural parameters [17]. The algorithm would take care of advanced geometry that goes into the different bracket connections that the company currently possesses. Thus, flexibility is achieved with the support from parametric modelling. Manual design can be avoided as complete solution is generated with different configurations. Moreover, platform architecture and how it is communicated is important when defining the rule of different configurations [9]. The execution is the same, and faster than selecting different components from a component library where set of solutions are pre-defined. Thus, a robust platform offering a rulebased approach can be developed with the help of parametric modelling. It has the ability to pre-check a model, such as geometry overlaps, rules for attribute and name, object existence and others, more detailed check [20]. To achieve this flexibility in connector design, the designer must identify the components to be modified and then determine how such changes propagate through different attributes.

Developing a rule-based product platform leverages the parametric modeling capabilities of BIM tools to automate the modelling process. The result shows that easy and quick modelling of connectors is possible, and the connections can be made automatically with options for adapting to the alternative design settings that enable design automation [13]. With parametric modelling approach, the rules and constraints are defined to control all possible collisions between these elements. The elements of the bracket are automatically modified, which shortens the modelling time and improves the quality. When members sizes are changed, the connections are automatically alternated 
according to designer's settings, which allows the accurate design [25]. Moreover, individual drawings can be generated from the model by using the filter option in Tekla that helps to avoid detailing of each bracket from scratch. The algorithm has been programmed in order to handle fluctuating customer requirements and to maintain the capabilities of a building component having ETO characteristics. Furthermore, this new method could support the existing platform to evolve as the algorithm can be updated and add more functionalities to become more agile. Thus, the study presents a novel approach in creating flexibility for the bracket platform with boundary conditions from a post and beam based construction. The case company can be able to make an impact on their design lead time with this approach by generating algorithms for all different types of connectors used for the building system. The result show that the integration of parametric support to BIM would assist designers in decision making and significantly reduces the possibility of inconsistencies. Therefore, the critical factors addresed are the time, cost, customisation and flexibility aspects when implementing parametric modelling approach in the design process [8]. The main limitation of parametric modelling is that skilled workers are required for coding the rules in computer language. A logical approach should be followed and high-level of expertise is needed to define, maintain, managing the algorithm over time, and verify the result to get a accurate outcome. It would consume a considerable amount of time and effort in the beginning while creating the algorithm. The result generated from this research is limited to a type of steel connector (bracket) used in the building system. As a future study, the case company can generate algorithms for other types of connectors for a significant impact on design improvement and validate the results. Moreover, the applicablity of the methodology can be tested and scaled to other type of building systems with components having ETO nature and be considered for future studies.

\section{Conclusion}

This article presents the development of a flexible product platform to support the design process of industrialised house building. A case study illustrates how a flexible product platform with parametric modelling approach can be developed and used to design building components having an engineer-to-order characteristics. The result shows that the parametric modelling based product development in the building industry offers flexibility in the design process and supports customization. The findings also provide an overview of the magnitude of the challenge associated to the design of connectors for glulam post and beam buildings. Thus, parametric modelling is a promising design automation tool to generate customised building components and facilitate and build a flexible platform. The approach provides a path forward to improve the design process of connectors and offer a flexible building system that can respond to future uncertainties. The results reveal that the way in which the flexibility is incorporated in the component such as the beam profile, number of screws in primary and secondary member, should consider when designing a flexible product platform for bracket connection.

\section{Acknowledgement}

We would like to thank all participants from the case company for vaulable contribution, Prowood and the knowledge foundation for the financial support of this research project. 


\section{References}

[1] L. Welin and L. Bildsten, The housing market in Sweden: a political-historical perspective. 2017, https://portal.research.lu.se/portal/files/29191948/CEO2017_paper_4.pdf, accessed July, 12020. Boverket, Svenska byggkostnader $i$ en internationell jämförelse \& Myndigheten för samhällsplanering byggande och boende. 2014, Available: http://www.boverket.se/. G. Jansson, H. Johnsson and D. Engström, Platform use in systems building. Construction Management and Economics, 2014, Vol. 32 (1-2), pp. 70-82. Söderholm, E., Applicability of continuous improvements in industrialised construction design process, lic thesis, Luleå tekniska universitet, 2010. design processes. Architectural Eng. and Design Mangmt., 2015, Vol. 11(5), pp. 360-375. J. Wortmann, A classification scheme for master production scheduling, in Efficiency of manufacturing systems. Springer, London, 1983, pp. 101-109.

B.L. Hansen, Development of industrial variant specification systems. 2003,IKON Tekst \& Tryk. S. Thajudeen, M. Lennartsson, and F. Elgh. Challenges and critical success factors for the design phase in Swedish industrialised house building. In 35th Annual ARCOM Conference, 2-4 September 2019, Leeds, UK. 2019, pp. 34-43.

[9] M.H. Meyer, The power of product platforms : building value and cost leadership, Free Press, New York, 1997.

[10] Robertson, D. and K. Ulrich, Planning for product platforms, Sloan management review, 1998, Vol. 39(4), pp. 19.

[11] S. André, The Design Platform Approach-Enabling platform-based development in the engineerto-order industry, PhD thesis, Jönköping University, School of Engineering, 2019.

[12] D. Raudberget, F. Elgh, R. Stolt, J. Johansson and M. Lennartsson, Developing agile platform assets-exploring ways to reach beyond modularisation at five product development companies, International Journal of Agile Systems and Management, 2019, Vol. 12(4), pp. 311-331.

[13] M. Sandberg, R. Gerth, W. Lu, G. Jansson, J. Mukkavaara, and T. Olofsson, Design automation in construction: An overview. In 33rd CIB W78 Conf., Oct. 31st-Nov. 2nd, Australia. 2016.

[14] B. Medjdoub, and G. Bi, Parametric-based distribution duct routing generation using constraintbased design approach. Automation in Construction, 2018, Vol. 90, pp. 104-116.

[15] P. Jensen, T. Olofsson, and H. Johnsson, Configuration through the parameterization of building components. Automation in Construction, 2012, Vol. 23, pp. 1-8.

[16] G. Lee, R. Sacks, and C.M. Eastman, Specifying parametric building object behavior (BOB) for a building information modeling system. Automation in construction, 2006, Vol. 15(6), pp. 758-776.

[17] E.S. Suh, O.L. De Weck, and D. Chang, Flexible product platforms: framework and case study. Research in Engineering Design, 2007, Vol. 18(2), pp. 67-89.

[18] X. Han, R. Li, J. Wang, G. Ding and S. Qin, A systematic literature review of product platform design under uncertainty. Journal of Engineering Design, 2020, Vol. 31(5), pp. 266-296.

[19] C.M. Eastman, C. Eastman, P. Teicholz, R. Sacks, BIM handbook: A guide to building information modeling for owners, managers, designers, engineers and contractors. Wiley, Hoboken, 2011.

[20] Eastman, C., Lee, J.M., Jeong, Y.S. and Lee, J.K, Automatic rule-based checking of building designs. Automation in construction, 2009, Vol. 18(8), pp. 1011-1033.

[21] W. Jabi, Parametric design for architecture, Laurence King Publ., London, 2013.

[22] R. Sacks, C.M. Eastman, and G. Lee, Parametric 3D modeling in building construction with examples from precast concrete. Automation in construction, 2004, Vol. 13(3), pp. 291-312.

[23] V. Singh, N. Gu, and X. Wang, A theoretical framework of a BIM-based multi-disciplinary collaboration platform. Automation in construction, 2011, Vol. 20(2), pp. 134-144.

[24] G.P. Monizza, C. Bendetti, and D.T. Matt, Parametric and Generative Design techniques in massproduction environments as effective enablers of Industry 4.0 approaches in the Building Industry. Automation in Construction, 2018, Vol. 92, pp. 270-285.

[25] S. Khalili-Araghi, and B. Kolarevic, Variability and validity: Flexibility of a dimensional customization system. Automation in Construction, vol. 109, 2020, paper 102970.

[26] Blessing, L.T. and A. Chakrabarti, DRM: A Design Research Methodology. Springer, London, 2009: 